\title{
Direct and indirect measurements relevant to the assessment of fatigue of the respiratory muscles - review
}

\author{
${ }^{1}$ Nałęcz Institute of Biocybernetics and Biomedical engineering, Ks. Trojdena 4, 02-109 Warsaw, Poland \\ phone: (+48 22) 6599143, fax: (+48 22) 6597030 \\ e-mail: bozena@ibib.waw.pl
}

The purpose of this review is to present selected tests available with the potential to detect the development of respiratory muscle fatigue in normal subjects and patients. All reviewed techniques represent a part of a variety of measures and indices, which have been employed to assess this complex process at the present time.

Key Words: muscle fatigue, fatigue indicator, test of respiratory muscle fatigue.

\section{Introduction}

Muscle fatigue has been defined as a loss of capacity to develop force in response to a load which is reversible by rest $[1-2,44-45]$. In accordance with this definition, respiratory muscle fatigue, potentially, can be documented by measuring a decrease or increase in specific respiratory markers.

Muscle fatigue is a complex phenomenon [20]. Most tests are suitable for detecting the presence of only one component of muscle fatigue $[42,47]$, so complete characterization of fatigue requires a complex series of assessments. The necessity to make serial measurements of an index of muscle force generation over time to detect fatigue is a particularly difficult endeavor for the respiratory system. A large number of variables (i.e., lung volume, muscle interaction, thoracoabdominal configuration) can vary over time and all these factors can influence the relationship between muscle force and pressure generation $[47,49]$. 
In the research environment, breathing pattern analysis [32, 51], measurement of thoracoabdominal motion [19], serial measurement of maximal voluntary respiratory pressures [52], assessment of maximum relaxation rates [27], frequency domain EMG analysis [43], and measurement of respiratory muscle pressures in response to electrical $[3,56]$ or magnetic [37-38] nerve simulation are all techniques that can be used to assess the evolution of respiratory muscle fatigue. This review presents the first four of these specific markers.

\section{Specific markers of respiratory muscle fatigue}

In this review, the breathing pattern analysis, measurement of thoracoabdominal motion, serial measurement of maximal voluntary respiratory pressures and assessment of maximum relaxation rates are presented.

\section{Breathing pattern analysis}

A part of the routine respiratory surveillance of patients is monitoring breathing frequency. This parameter can be easily counted at the bedside and should be included in standard monitoring $[10,14,18]$. Test is simple and noninvasive. Rationale of use this test can be rapid shallow breathing, characterized by high breathing frequency and low tidal volume. These conditions are associated with an increased respiratory workload and a reduced respiratory muscle capacity and may therefore potentially lead to respiratory muscle fatigue [17, 31].

The second parameter of breathing pattern is tidal volume. Volume measurements can be made by spirometric devices via a mouthpiece in non-intubated patients or by flow sensors built into modern ventilatory equipment and can be displayed on a breath-to-breath basis by these machines in intubated patients. To avoid artifacts from mouthpiece placement, it is possible to noninvasively monitor tidal volume by respiratory inductance plethysmography [14].

The disadvantage of these methods is fact that rapid shallow breathing is most likely a reflex response to an increase in the respiratory workload and not the consequence of the respiratory muscle fatigue per se $[32,53]$. The application of this test indicates that although rapid shallow breathing may accompany respiratory muscle fatigue [31-35], it cannot be considered a specific marker of fatigue and tidal volume and breathing frequency should not be used as specific indicators of the development of this complex phenomenon. 


\section{Measurement of thoracoabdominal motion}

The analysis of thoracoabdominal (e.g., diaphragmatic, abdominal and of the rib cage inspiratory muscles) motion is useful to detect a specific forms of respiratory muscle dysfunction and an increase in the fatiguing ventilatory load $[21,25,53]$.

This test is simple and noninvasive; the patient is placed in a recumbent position and a trained observer is conducting a visual inspection of breathing movements for several minutes [55]. The disadvantages of this method are connected with the abnormal patterns of thoracoabdominal motion as respiratory alternant [30] or abdominal paradox [54], which are not specific for respiratory muscle fatigue [46]. These patterns can occur during the application of low, non-fatiguing respiratory loads [48]. Thus, abnormal thoracoabdominal motion should be viewed as reflecting an increased ventilatory load, which in itself may or may not induce respiratory muscle fatigue [50].

The application of this analysis is useful for some clinical routine practice, but the lacks of specificity for detecting respiratory muscle fatigue cause that it is should not be used as fatigue indicator.

\section{Serial measurement of maximal voluntary respiratory pressures}

In several investigations, to detect fatigue of inspiratory muscles, one could measure either esophageal pressure and gastric pressure, maximal static inspiratory pressure or maximal transdiaphragmatic pressure.

\section{The pressure - time index of the diaphragm and inspiratory rib cage muscles}

Two pressures - time indices characterize the operational conditions of the inspiratory muscles with respect to their fatigue threshold.

The first parameter is the pressure - time index of the diaphragm, which is defined as: $\mathrm{PT}_{\mathrm{di}}$ $=\left(\right.$ Pdi $\left./ P_{d i}, \max \right)\left(T_{i} / T_{\text {tot }}\right)$, where $P_{d i}$ is the mean transdiaphragmatic pressure generated per breath, $\mathrm{P}_{\mathrm{di}}$ max is maximal transdiaphragmatic pressure, $T_{i}$ is inspiratory time, $T_{\text {tot }}$ is total breath time [11-12]. The critical value of $\mathrm{PT}_{\mathrm{di}}$ is $0.15-0.18$ for breathing accomplished predominantly with diaphragm [7-8]. It means that fatigue of inspiratory muscles of subjects submitted to external inspiratory loads will occur when the level of pressure - time generated exceeds this 
critical value. Below this threshold, breathing can be sustained for more than 1 hour without evidence of fatigue $[5-6,15]$.

The second parameter is the pressure - time index of the inspiratory rib cage muscles. In most situations of inspiratory loads, the spontaneous breathing is characterized by predominant recruitment of inspiratory rib cage muscles than the diaphragm. Under these circumstances, this index is defined as: $\mathrm{PT}_{\mathrm{rci}}=\left(\mathrm{P}_{\mathrm{pl}} / \mathrm{P}_{\mathrm{pl}}\right.$ max $)\left(\mathrm{T}_{\mathrm{i}} / \mathrm{T}_{\text {tot }}\right)$, where $\mathrm{P}_{\mathrm{pl}}$ is mean pleural pressure generated per breath, $\mathrm{P}_{\mathrm{pl} \text {, max }}$ is maximal pleural pressure. With this breathing pattern, the critical value of PT rci is 0.30 [7-8].

Pressures measurements are performed with balloon - catheter systems; the measurement of esophageal pressure ( $\mathrm{Pes}_{\mathrm{es}}$ ) is required to compute $\mathrm{PT}_{\text {rci }}$ and the measurement of both gastric $\left(\mathrm{P}_{\mathrm{ga}}\right)$ and esophageal pressures - to compute $\mathrm{PT}_{\mathrm{di}}$. The critical values of pressure - time indices in most patients and in healthy subjects breathing against external loads remain to be measured although a number of pathological factors may influence muscle performance and the critical thresholds may different in clinical conditions. As a consequence, these two indices may allow the assessment of the risk of fatigue before actual task failure occurs, but in several investigations $\mathrm{PT}_{\text {di }}$ and $\mathrm{PT}_{\text {rci }}$ are considered the instrument to gauge the level of muscle function rather than a specific marker of fatigue $[9,58]$.

\section{Maximal static inspiratory pressure}

Measurement of maximal static inspiratory pressure $\left(\mathrm{P}_{\mathrm{I}, \mathrm{max}}\right)$ can be used to detect inspiratory muscle fatigue in volunteers breathing against external loads, maximal voluntary hyperpnoea, labor or marathon running $[22,28,39]$.

$\mathrm{P}_{\mathrm{I}, \max }$ is measured at the mouth and the method is noninvasive. The limitations of this test are connected with difficulties in ensuring maximal volitional effort in patients.

\section{Maximal transdiaphragmatic pressure}

Diaphragmatic fatigue has been documented by a transient fall in maximal transdiaphragmatic pressure $\left(P_{d i, m a x}\right)$ after breathing with diaphragm emphasis against external loads or high-intensity exercise [29, 35-36]. 
The measurement is invasive with standard balloon - catheter systems. This test is useful to assess the strength of the diaphragm and can be used to detect inspiratory muscle fatigue in motivated subjects, but not in patients $[16,40,57]$.

\section{Assessment of maximum relaxation rates}

On cessation of loading and contraction, respiratory muscles relax at a rate determined by their histological structure $[23,50]$. During fatigue, relaxation rate declines as a result of a slower uptake of calcium. The relaxation rate can be assessed during intermittent contractions against loads, during sniffs and during phrenic nerve stimulations. When fatigue is induced by breathing against external loads, the inspiratory muscle relaxation rate falls early and then recovers quickly and stabilizes within 5 to 10 minutes [27].

During various types of intermittent contractions, the rate of decay of the esophageal pressure $\left(P_{\text {es }}\right)$ and of the mean transdiaphragmatic pressure generated per breath $\left(P_{\mathrm{di}}\right)$, reflects the relaxation rate of inspiratory muscles and of the diaphragm, respectively $[24,26]$. The measurement of inspiratory muscle relaxation rate requires relatively simple pressure measurement system. Standard balloon - catheter system are used to measure the esophageal pressure $\left(P_{\text {es }}\right)$ and gastric pressure $\left(P_{\text {ga }}\right)$ from which the mean transdiaphragmatic pressure generated per breath $\left(P_{d i}\right)$ is obtained. The maximal relaxation rate (MRR) is calculated as a first derivative of pressure with respect to time over the first half of the relaxation curve [16, 33]. Analysis of the MRR is best done with a computer program [16].

The muscle relaxation rate slows at an early stage during fatiguing contractions and may therefore indicate that inspiratory muscle fatigue is incipient. The measurements of this indicator can be used to detect an early sign of fatigue in subjects and to detect fatiguing contractions during exercise in patients with chronic obstructive pulmonary diseases or during weaning trials from a respirator $[13,41]$. This test is useful only for clinical research.

\section{Conclusion}

It is difficult to indicate the best method to directly assess the development of respiratory muscle fatigue at present time. Of the tests reviewed: breathing pattern analysis and measurement of thoracoabdominal motion are nonspecific indices that do not directly measure 
fatigue. Analysis of the pressure - time index provides a useful conceptual framework, but not a specific test of fatigue. In the research environment, all these techniques can be used to assess the evolution of respiratory muscle fatigue.

The clinical area is open for an objective test of the development of respiratory muscle fatigue.

\section{Reference}

[1] Aldrich TK. Central fatigue of the rabbit diaphragm. Lung 1988; 166(4): 233-41.

[2] Aldrich TK. Respiratory muscle fatigue. Clin Chest Med 1988; 9(2): 225-36.

[3] Aubier $M$ et al. Detection of diaphragmatic fatigue in man by phrenic stimulation. J Appl Physiol 1981; 50(3): 538-44.

[4] Babcock MA et al. Hypoxic effects on exercise-induced diaphragmatic fatigue in normal healthy humans. J Appl Physiol 1995; 78(1): 82-92.

[5] Babcock MA et al. Aerobic fitness effects on exercise-induced low-frequency diaphragm fatigue. J Appl Physiol 1996; 81(5): 2156-64.

[6] Bailey SJ, Romer LM, Kelly J, Wilkerson DP, DiMenna FJ, Jones AM. Inspiratory muscle training enhances pulmonary $\mathrm{O}(2)$ uptake kinetics and high-intensity exercise tolerance in human. J Appl Physiol 2010; 109(2): 457-68.

[7] Bazzy AR, Donnelly DF. Diaphragmatic failure during loaded breathing: role of neuromuscular transmission. Journal of Applied Physiology 1993; 74(4): 1679-1683.

[8] Bellemare $F$, Bigland-Ritchie B. Assessment of human diaphragm strength and activation using phrenic nerve stimulation. Respir Physiol 1984; 58(3): 263-77.

[9] Bellemare F, Bigland-Ritchie B, Woods JJ. Contractile properties of the human diaphragm in vivo. J Appl Physiol 1986; 61(3): 1153-61.

[10] Broeders E, Molema J, Hop WC, Folgering HT. Bronchial challenge, assessed with forced expiratory manoeuvres and airway impedance. Respir Med 2005; 99(8): 1046-52.

[11] Bye PT et al. Ventilatory muscles during exercise in air and oxygen in normal men.J Appl Physiol 1984; 56(2): 464-71.

[12] Bye PT et al. Ventilatory muscles function during exercise in air and oxygen in patients with chronic air-flow limitation. Am Rev Respir Dis 1985; 132(2): 236-40. 
[13] Chang AT, Boots RJ, Brown MG, Paratz J, Hodges PW. Reduced inspiratory muscle endundance following successful weaning prolonged mechanical ventilation. Chest 2005; 128(2): .

[14] Cohen CA et al. Clinical manifestations of inspiratory muscle fatigue. Am J Med 1982; 73(3): 308-16.

[15] Dayer MJ, Hopkins NS, Ross ET, Jonville S, Sharhar T, Kearney M, Moxham J, Polkey MI. Does symptom-limited cycle exercise cause low frequency diaphragm fatigue in patients with heart failure? Eur J Heart Fail 2006; 8(1): 68-73.

[16] Esau SA, Bye PT, Pardy RI. Changes in rate of relaxation of sniffs with diaphragmatic fatigue in humans. J Appl Physiol 1983; 55(3): 731-35.

[17] Gigliotti F, Binazzi B, Scano G. Does training of respiratory muscles affect exercise performance in healthy subjects?. Respir Med 2006; 100(6): 1117-20.

[18] Guenette JA, Sheel AW. Physiological consequences of high work of breathing during heavy exercise in humans. J Sci Med Sport 2007; 10(6): 341-50.

[19] Hostettler S, Illi SK, Mohler E, Aliverti A, Spengler CM. Chest wall volume changes during inspiratory loaded breathing. Respir Physiol Neurobiol 2011; 175(1): 130-39.

[20] Kabitz HJ, Walker D, Schwoerer A, Sonntag F, Walterspacher S, Roecker K, Windisch W. New physiological insights into exercise-induced diaphragmatic fatigue. Respir Physiol Neurobiol 2007; 158 (1): 88-96.

[21] Kabitz HJ, Walker D, Schwoerer A, Walterspacher S, Sonntag F, Schlager D, Roecker K, Windisch $W$ Diaphragmatic fatigue is counterbalanced during exhaustive long-term exercise. Respir Physiol Neurobiol 2010; 172 (3): 106-13.

[22] Kabitz HJ, Walker DJ, Schwoerer A, Schlager D, Walterspacher S, Storre JH, Roecker K, Windisch W, Verges S, Spengler CM. Biometric approximation of diaphragmatic contractility during sustained hyperpnea. Respir Physiol Neurobiol 2011

[23] Klimathianaki M, Vaporidi K, Georgopoulos D. Respiratory Muscle Dysfunction in COPD: From Muscles to Cell. Curr Drug Targets 2011; 12 (4): 478-88.

[24] Kyroussis D, Mills GH, Hamnegard CH, Wragg S, Road J, Green M, Moxham J. Inspiratory muscle relaxation rate assessed from sniff nasal pressure. Thorax 1994; 49(11): 1127-33.

[25] Kyroussis D, Mills GH, Polkey MI, Hamnegard CH, Wragg S, Road J, Green M, Moxham J. Effect of maximum ventilation on abdominal muscle relaxation rate. Thorax 1996; 51 (5): 510-15. 
[26] Kyroussis D, Johnson LC, Hamnegard CH, Polkey MI, Moxham J. Inspiratory muscle maximum ralaxation rate measured from submaximal sniff nasal pressure in patients with severe COPD. Thorax 2002; 57 (3): 254-57.

[27] Levy RD, Esau SA, Bye PT, Pardy RI. Relaxation rate of mouth pressure with sniffs at rest and with inspiratory muscle fatigue. Am Rev Respir Dis 1984; 130 (1): 38-41.

[28] Loke J, Mahler DA, Virgulto JA. Respiratory muscle fatigue after marathon running. J Appl Physiol 1982; 52(4): 821-4.

[29] Luo YM, Hart N, Mustafa N, Lyall RA, Polkey MI, Moxham J. Effect of diaphragm fatigue on neuronal respiratory drive. Am Rev Respir Dis 2001; 90(5): 1691-99.

[30] Macklem PT, Cohen C, Zagelbaum G, Roussos C. The pathophysiology of inspiratory muscle fatigue. Ciba Found Symp 1981; 82: 249-63.

[31] Mador MJ, Acevedo FA. Effect of respiratory muscle fatigue on breathing pattern during incremental exercise. Am Rev Respir Dis 1991; 143 (3): 462-68.

[32] Mador MJ. Respiratory muscle fatigue and breathing pattern. Chest 1991; 100 (5): 1430-35.

[33] Mador MJ, Kufel TJ. Effect of inspiratory muscle fatigue on inspiratory muscle relaxation rates in healthy subjects. Chest 1992; 102(6): 1767-73.

[34] Mador MJ, Tobin MJ. The effect of inspiratory muscle fatigue on breathing pattern and ventilatory response to CO2. J Physiol 1992; 455: 17-32.

[35] Mador MJ, Magalang UJ, Rodis A, Kufel TJ. Diaphragmatic fatigue after exercise in healthy human subjects. Am Rev Respir Dis 1993; 148 (6 Pt 1): 1571-75.

[36] Mador MJ et al. Diaphragmatic fatigue and high-intensity exercise in patients with chronic obstructive pulmonary disease. Am J Respir Crit Care Med 2000; 161(1): 118-23.

[37] Mador MJ, Khan S, Kufel TJ. Bilateral anterolateral magnetic stimulation of the phrenic nerves can detect diaphragmatic fatigue. Chest 2002; 121(2): 452-8.

[38] Man WD, Moxham J, Polkey MI. Magnetic stimulation for the measurement of respiratory and skeletal muscle function. Eur Respir J 2004; 24 (5): 846-60.

[39] McKenzie DK et al. Central and peripheral fatigue of human diaphragm and limb muscles assessed by twitch interpolation. J Physiol 1992; 454: 643-56.

[40] McKenzie DK, Butler JE, Gandevia SC. Respiratory muscle function and activation in chronic obstructive pulmonary disease. J Appl Physiol 2009; 107(2): 621-9.

[41] Mier-Jedrzejowicz AK et al. Assessment of diaphragm weakness. Am Rev Respir Dis 1988; 137(4): 877-83.

[42] Mioxham J, Jolley C. Breathlessness, fatigue and the respiratory muscles. Clin Med 2009; 9(5): 448-52. 
[43] Moxham J et al. Changes in EMG power spectrum (high-to-low ratio) with force fatigue in humans. J Appl Physiol 1982; 53(5): 1094-9.

[44] Moxham J et al. Contractile function and fatigue, in Human muscle fatigue: physiological mechanisms, W.J. Porter R, Editor. 2001, Pitman Medical: London. 197- 209.

[45] Moxham J. Respiratory muscle fatigue: mechanisms, evaluation and therapy. Br J Anaesth 1990; 65(1): 43-53.

[46] Nava $S$ et al. Evidence of acute diaphragmatic fatigue in a "natural" condition. The diaphragm during labor. Am Rev Respir Dis 1992; 146(5 Pt 1): 1226-30.

[47] Roussos C, Aubier M. Neural drive and electromechanical alterations in the fatiguing diaphragm. Ciba Found Symp 1981; 82: 213-33.

[48] Roussos $C$ et al. Fatigue of inspiratory muscles and their synergic behavior. Journal of Applied Physiolog, 1979; 46(5): 897-904.

[49] Satoshi Kuwabara. Excitability testing: From nerve to muscle. Clinical Neurophysiology $2011 ; 122(4): 639-640$.

[50] Scardella AT, Petrozzino JJ, Mandel M, Edelman NH, Santiago TV. Endogenous opioid effects on abdominal muscle activity during inspiratory loading. J Appl Physiol 1990; 69 (3): 1104-09.

[51] Segizbaeva MO, Aleksandrova NP. Effects of oxygen breathing on inspiratory muscle fatigue during resistive load in cycling men. J Physiol Pharmacol 2009; 60 Suppl 5: 111-5.

[52] Taylor BJ, Romer LM. Effect of expiratory resistive loading on inspiratory and expiratory muscle fatigue. Respir Physiol Neurobiol 2009; 166(3): 164-74.

[53] Tobin MJ, Laghi F, Brochard L. Role of the respiratory muscles in acute respiratory failure of COPD: lessons from weaning failure. J Appl Physiol 2009; 107(3): 962-70.

[54] Tobin, M.J., et al., Does rib cage-abdominal paradox signify respiratory muscle fatigue? J Appl Physiol 1987; 63(2): 851-60.

[55] Tomczak SE et al., Diaphragm fatigue after submaximal exercise with chest wall restriction. Med Sci Sports Exerc 2011; 43(3): 416-24.

[56] Walter JS, Dunn RB, Wurster RD, Laghi F. Microstimulators and intramuscular hook electrodes for the stimulation of respiratory muscles. J Spinal Cord Med 2007; 30 (4): 33845.

[57] Walker DJ et al., Characteristics of diaphragmatic fatigue during exhaustive exercise until task failure. Respir Physiol Neurobiol 2011; 176(1-2): 14-20.

[58] Yan S, Similowski T, Gauthier AP, Macklem PT, Bellemare F. Effect of fatigue on diaphragmatic function at different lung volumes. J Appl Physiol 1992; 72 (3): 1064-67. 